\title{
COMMENTARY
}

Alexander Levit, $\mathrm{MD} / \mathrm{PhD}{ }^{1}$

Robert Bortolussi, MD FRCPC FCAHS 2 \section{Canadian physician-scientists: Perspectives of four experts \\ Challenges and opportunities for future}

${ }^{1}$ Department of Psychiatry, University of British Columbia, Vancouver, BC

2 Dalhousie University, Halifax, NS

\begin{abstract}
In this series of interviews, the Clinical and Investigative Medicine editorial team gathered expert opinions on the future of physician-scientist training and career prospects in Canada. This was inspired by recent publications that voiced concerns over the diminishing support for the physician-scientist in Canada and the United States. For this editorial, the term physician-scientist was intentionally broad and inclusive; referring to individuals who identify both clinical work and biomedical or healthcare research as major components of their career. The following leaders in medical research or research funding shared their perspectives: Roderick R. McInnes; Michel G. Bergeron; Thomas J. Marrie; and Bev J. Holmes.
\end{abstract}

\section{Correspondence to:}

Alexander Levit

Email: alevit@alumni.ubc.ca 


\section{Introduction}

In this series of interviews, the Clinical and Investigative Medicine editorial team set out to gather expert opinions on the future of physician-scientist training and career prospects in Canada. This article was inspired by recent publications that voiced concerns over the diminishing support for the physician-scientist in Canada and the United States (US) [1,2]. For the purpose of this editorial, the term "physician-scientist" is intentionally broad and inclusive, referring to individuals that identify both clinical work and research in biomedicine and healthcare as major components of their career. However, interviewees did offer their thoughts and qualifications on this terminology. We spoke with Roderick R. McInnes, Michel G. Bergeron and Thomas J. Marrie, exceptional clinician-scientists who had all started their careers in the early 1970s; they shared their perspectives on how the career has evolved and the future of the career. We also spoke with Bev J. Holmes, a leader in health research funding, who shared her perspectives on how relations between funders and researchers can be made more constructive.

Roderick McInnes received his MD from Dalhousie University and his $\mathrm{PhD}$ from McGill University before extending his training as a post-doc at the Massachusetts General Hospital. Pediatric and genetic clinical training was attained at both Montreal Children's and Boston Children's Hospitals. He made important advances on the development of the eye and retina and the pathophysiology of inherited retinal degenerations. From 2000-2010, Rod was the inaugural Scientific Director of the Institute of Genetics of the Canadian Institutes of Health Research (CIHR) and was appointed Acting President of the CIHR in 2017-2018. He was appointed to the Order of Ontario in 2008 and the Order of Canada in 2009. He is currently a Professor in the departments of Human Genetics and of Biochemistry at McGill University, holds the Alva Chair in Human Genetics, and is the Director of the Lady Davis Institute of the Jewish General Hospital.

Michel Bergeron attained his MD at Université Laval, trained in internal medicine at McGill University and in microbiology and infectious disease at Tufts University and Massachusetts Institute of Technology. Michel made transformative contributions to the development of antimicrobials and rapid DNA-based microbe assays. In 1974, he founded the Infectious Disease Research Centre (CRI) at the University Hospital, which went on to become a centre of research excellence. He created two successful molecular diagnostics companies: IDI (now BD) and
GenePOC (now Meridian Bioscience). He was appointed to the Order of Canada in 2010, received the Ernest C. Manning Innovation Principal Award in 2016, and was inducted into the Canadian Medical Hall of Fame in 2017. $\mathrm{He}$ is currently a Professor in the Department of Microbiology, Infection and Immunology at Université Laval.

Thomas Marrie attained his MD and trained in internal medicine at Dalhousie University before pursuing an Infectious Disease fellowship at the University of Manitoba. He went on to develop crucial improvements in the diagnosis and management of community-acquired pneumonia and was a founding member of the Canadian Foundation for Infectious Disease. In 2014, Tom was appointed to the Order of Canada. Tom has held the position of Dean of Medicine at both the University of Alberta and Dalhousie University.

Bev Holmes completed her MA and a PhD at Simon Fraser University and holds adjunct appointments at University of British Columbia's School of Population and Public Health and Simon Fraser University's Faculty of Health Sciences. Bev is Vice President of Friends of CIHR and led the development of BC SUPPORT unit; a multipartner organization created to support, streamline, and increase patient-oriented research. She co-chaired the National Alliance of Provincial Health Research Organizations in 2018 and 2019. Since 2017, Bev has been President and CEO of the Michael Smith Foundation for Health Research, British Columbia's health research funding agency. In this position, she has advanced the foundation's mission to support health researchers, including many physician-scientists, by developing talent, increasing funding and facilitating knowledge translation.

\section{What is your general outlook on the future of physician-scientist training and career prospects in Canada?}

TJM: I think it is very important that clinician-scientists continue to maintain meaningful clinical responsibility, and that is why I prefer the term clinician-scientist over physician-scientist. After all, one can be a physician without being a clinician. Continued clinical responsibility maintains two very key aspects of a dual career; firstly, the clinicianscientist can serve as a role model for other clinicians, and secondly, clinical exposure offers a continued source of research questions that can be taken back to the lab.

If you are a promising young clinician-scientist, many universities will try to recruit you and offer protected time. 
Most places in Canada now recognize the value in this but for sure, the capacity for such positions will differ across universities. On a different note, my impression is that the rate of burnout is lower among clinician-scientists. I think this is one of the perks of a multi-faceted career as your interests and work remains varied and evolves over time there's always another problem to solve and it's incredibly exciting when you solve those problems.

RRM: I think the future is challenging but there continue to be important pathways for the training of physicianscientists. Firstly, there are very successful $\mathrm{MD} / \mathrm{PhD}$ programs across the country; however, it would be ideal to have more data on where graduates from these programs end up. Another pathway in supporting physician-scientists early in their career are endowment funds or private research foundations. One such excellent program is the "Career Awards for Medical Scientists" from the Burroughs Wellcome Fund. Such opportunities continue to be more established in the US, but there are certainly options in Canada as well.

MGB: I'm naturally an optimistic person, but I do have concerns regarding recruitment as I am seeing fewer and fewer young applicants for physician-scientist positions. I think there are several factors involved. Firstly, the duration of training required likely limits the number of people that would consider pursuing a physician-scientist career. Secondly, I feel that there may be an inadequate number of training opportunities in Canada, even for those who would consider dual training as MD and PhD. Thirdly, I also see a concerning amount of "intellectual in-breeding" in Canada, and I think it's important that this be avoided. I encourage my graduate and post-graduate students or fellows to seek training at multiple sites so that they can develop new perspectives. Of course, this adds to the stress of training, but it is worth it.

It would be useful to have data on how many such positions are available in Canada and how successful these programs are. On a higher level, the government also regulates how many future physicians-scientists will be allowed to train within a given discipline, which limits the positions available. Moreover, I am quite worried because governments are limiting the number of medical students and specialist positions throughout the country. So, overall, I think it is very hard to predict whether the physicianscientist career is protected in Canada!

BJH: I think that where and how health professionals conduct their research should diversify and that funding agencies should support this_but funding agencies are only one small part of a much bigger picture. The role of the Michael Smith Foundation for Health Research (MSFHR) in BC's ecosystem is to support our province's research talent, and "research talent" is a fast-evolving concept these days. Fewer people with $\mathrm{PhDs}$ are getting and seeking tenure in academia, and more are working in varied settings, including industry, community, and health care. Recognizing the need to support a broad range of research talent, MSFHR and other funding institutions have recently expanded our more traditional programming beyond salary awards for scholars and trainees (career researchers); we now have a range of programs, including one for health professional investigators (clinician-scientists) and innovators-applications from this type of "talent" can't be evaluated alongside those of career researchers. However what we are seeing is that although our research ecosystem partners think this type of programming is important, health professionals, including physicians, do not always get the research support they need (for example, buy-out time, access to infrastructure, and even validation from leaders). I believe those funding clinician-scientists need to work closely with research and health system partners to ensure the support for this critical role.

\section{What are some of the biggest challenges for aspiring physician-scientists today? And for established physician-scientists? What might be some key ways to address these challenges?}

RRM: For physician-scientists at all stages, the most pressing challenge today is the increasing complexity of research, particularly for physician-scientists engaged in basic science research. This complexity is reflected in the major journals where the number of authors on a single article continues to increase. This challenge holds true even for full-time non-MD researchers, with whom physicianscientists must compete with for funding at national and even international levels. Furthermore, with basic-science largely being a discovery-based endeavour, it is more difficult to guarantee deliverables and it often takes a long time to achieve research goals. We're at a time when no one person or even one group of researchers can address all components of a significant research question, so multidisciplinary collaboration will be crucial. We are also seeing more clinicians engaging in other areas of research such as epidemiology, quality improvement, and policy. These are no less intellectually challenging and often make a better fit with a clinician's experience and career.

For aspiring physician-scientists, work-life balance is a continual challenge. Family and financial obligations, plus 
the many years of training required for both patient care and research, are formidable hurdles. What amazes me are the number of exceptional people who manage to successfully balance all these obligations. An important factor in addressing work-life balance is the recognition of these challenges by research supervisors and program directors. One strategy to consider is to favour shorter research training periods in combined $\mathrm{MD} / \mathrm{PhD}$ programs, e.g. three year as opposed to five years to complete the $\mathrm{PhD}$, as is seen more often in the British system; this might limit opportunities for publication in major journals but can still instill a strong foundation for a successful research career.

The same challenges exist for senior physicianscientists. I can mostly speak for those in basic-science research and again, the great difficulty is the increasing complexity of science. I'm a human geneticist and I know the field well, but not all of genetics is immediately accessible to me anymore; I can't necessarily pick up an article in one of the major journals and be able to read it quickly and comfortably - that would have been unheard of 10-15 years ago, and shows how fast things are evolving.

MGB: While I think many will agree that physicianscientists are needed to lead transdisciplinary research, I don't know if there is enough support mentorship for aspiring physician-scientists today. This brings me to the definition of the physician-scientist-while there is a lot of emphasis on clinical care and research, it should not be forgotten that the physician-scientist must teach at all levels (undergraduates, graduates, postgraduates, residents and fellows)! I did not see enough reference to the role of physician-scientists as teachers, mentors, and role models in the article by Jain et al., but these roles are crucial for sustaining the future of physician-scientists. Accordingly, it's important that we "teach the future teachers" on how to be most effective. In my experience, outstanding role models and mentors where key to setting me on the path of my career as a physician-scientist.

I also think it's important that during the selection of trainees, and throughout the training process, we should emphasize the importance of innovation and rapid responsiveness especially in infectious diseases where new emerging pathogens like severe acute respiratory syndrome coronavirus 2 (SARS-CoV-2) arise. Throughout our careers, success continues to rely on both our continued creativity and grantsmanship as we pass a great deal of time (too much) writing grant applications.

The whole grant process can certainly pose a major challenge for both aspiring and established physician- scientists, and this reflects the rapid evolution of knowledge in science and medicine. Early in my career (1970-1990), individual researchers could secure a grant and successfully answer a meaningful research question. But now, it takes a multi-disciplinary team to accomplish this. I now have anthropologists, engineers, physicists, optics and photonics specialists, artificial intelligence and bioinformatics experts working in my team. We need to think big and be sure to include young investigators in such teams. Also, to help ensure the sustainability of research funding, it's important to secure grants from multiple agencies. Moreover, having multiple themes within a research program is absolutely necessary. Another important means to ensure sustainability of funding is to support your colleagues who fail to secure grants, so that one day they might help you in turn. In short, mentorship and collaboration (breaking silos) are key to overcoming many of the challenges faced by physicianscientists today. A good way to foster this is to organize cohesive transdisciplinary research groups that comprise individuals across all career stages.

TJM: The most obvious challenge for aspiring clinicianscientists is that it might take longer to complete your training. This makes managing debt and supporting a family much more difficult. The best way to deal with this is for trainees to minimize the up-front debt burden as much as possible and for universities to support trainees through programs such as tuition relief and scholarships.

For both junior and established clinician-scientists, securing protected time is likely one of the biggest challenges. This is where government can play an important part as many of the alternative funding plans for clinicianscientists (e.g., an 80/20 split in research/clinical time) are supported by government.

3. A central argument of the article by Jain et al. is that, at least in the US, there are no longer enough physicians engaged in biomedical research, being down to $1.5 \%$ of all physicians in 2012 from a peak of $4.7 \%$ in the $1980 \mathrm{~s}$ [2]. The absolute number of US physicians engaged in research as a major professional activity has also reduced [3]. While specific data in Canada have not been reported, Strong et al. similarly argue that the diminishing support for physician-scientist training in Canada is alarming and will lead to a gap in translational research [1]. Do you agree?

RRM: I think that all the aforementioned challenges have contributed to a worldwide decrease in the number of physicians entering research. The international research 
landscape now is very different and more competitive than it was in earlier decades; today's expectations likely need to be lower than they were in the "golden era" described by Jain et al., but we can definitely do better. To expect all academic physicians to be superb clinicians, researchers, and teachers is probably increasingly unrealistic now.

MGB: Yes and no-the person best positioned to identify gaps in healthcare and to test solutions is the physicianscientist. But the world is changing, and many non-MD researchers are doing terrific translational research; translational research is by no means exclusive to physicianscientists. I find that sometimes, it is felt to be taboo to discuss the differences between the physician-scientist and the basic scientist, but we should address this. So, what is the difference? It's very simple-PhD scientists are much better prepared for research than physicians. They have more research training and dedicate more time to research than MDs. These are just the facts. Nonetheless, it is very important that all medical trainees have the opportunity to develop a taste and a passion for research early in their training. As we are seeing decreasing numbers of physicianscientists, it is more important than ever that medical students and residents be required to pass a meaningful period of intensive research; e.g., at least one year. Additionally, even if the research time and skillsets which physicians may have are relatively limited when compared to that of those of the $\mathrm{PhD}$ researchers, this mandatory (one year) exposure to la méthode expérimentale should be effective in making them better clinicians and more effective in transdisciplinary collaborations, including with $\mathrm{PhD}$ researchers. Ensuring meaningful research exposure such as a mandatory research year will increase the number of physicians that might realize that being a physician-scientist is one of the most interesting careers there is as there are no limits for opportunities that are offered to us throughout our career.

TJM: I would love to have more specific data on this matter, including breakdowns of how much time clinicianscientists allocate to research and clinical responsibilities. These data should not be difficult to compile. But my general impression is that yes, there are now fewer physicians engaged in research. I think that the Canada Research Chairs and endowed chairs have helped in mitigating this but we don't have nearly enough people doing this kind of work. This certainly poses a problem for the future of translational research and that is why in my tenures as Dean, I've emphasized the importance of medical students having exposure to research. I would say that this should start even earlier-such as in high school.

There has been a diminishing requirement for a scientific background to get into medical school, and I think that this is a grave mistake. Of course, I have an appreciation for how a background in the humanities helps in medical school- I would never say no to that. But at the end of the day, while medicine is an art, it is still founded on science. So, it is essential to have a strong scientific background, and this demands research experience.

BJH: Most of the applicants for Michael Smith Foundation for Health Research (MSFHR) funding are physicians. They range from those who are highly trained and have been deeply immersed in research to those with less formal research training. This brings up what $I$ think is an important point-the definition of clinician-scientist or physician-scientist is somewhat loose. Sometimes it refers to people who have an $\mathrm{MD}$ and a $\mathrm{PhD}$, sometimes to people who are MDs and who have some research training and are involved in research. I do think that the former are critical, and ideally there would be more support for them. I also think the latter are critical as well, and that ideally it should not be just physicians who get trained and supported in research, but other clinicians (and health care decision makers as well, but that's another story). Which brings me to my main point - ideally research should be embraced in our health care system, and research and care should be more integrated. While I think there has been a move towards this, there are still some people who believe that research detracts from care, despite the growing evidence that research done close to practice improves care.

Clinician/physician-scientists, regardless of the definition, won't be successful or attracted to that work in the first place if the system doesn't embrace them and put in place the supports - and the culture - that they need. That is far beyond training and mentoring; it is about changing motivations and incentives (and disincentives) of a wide range of individuals and organizations and even systems. To this end, Jain et al. outline good recommendations [2].

\section{In the bygone days, medicine and science had more overlap. Do you believe that a single person, the "physician-scientist", is still the best person to tackle bench-to-bedside questions?}

RRM: The idea that basic scientists without clinical training do not value or engage in translational medicine is a total myth-I've never met a full-time basic scientist who was indifferent as to whether their work is of value to 
medicine and society. That being said, the types of questions prioritized by the full-time basic scientist and the full-time physician are often distinct from those raised by a physician-scientist. So, in addition to bridging pre-clinical and clinical studies, the perspective of the physicianscientist continues to be valuable.

MGB: Yes, the physician-scientists are the best prepared to lead bench-to-bedside questions but they are certainly not the only ones that play a crucial role in this process. Thus, physician-scientists will be far more successful by seeking out meaningful multi-disciplinary collaborations. The physician-scientist's advantage is that they can more efficiently identify deficiencies in our practice of medicine at the bedside and in the greater health system, and then turn to the lab to create innovative solutions at the bench, and then return to the bedside to apply these solutions in clinical practice. I often hear many argue that basic science is not accessible for physician-scientists, but I would discourage such a position as physician-scientists can and do make important discoveries at the basic science level. Physician-scientist are also best positioned to break research silos because of their broader vision; but to do this, physician-scientists should know that they can work at any level of the translational research spectrum that speaks to their research interests. In our research centre, half the professors are MDs while the other half are PhDs; synergy between those two groups is impressive, as we complement each other.

TJM: I would think so. It's hard for any person to tackle bench-to-bedside questions, but the clinician-scientist has acquired the knowledge, skills, and experience through both clinical and research curricula and exposure. There has been an important emergence of research led by nurses but, unlike MDs, nurses engaged in research are less likely to have to maintain clinical responsibilities. This may be different among nurse practitioners, but it remains to be seen how the culture develops in this relatively new profession.

BJH: I think we need physician-scientists, but they alone can't change patient outcomes. I believe they need to be embedded in an evidence-embracing system, with all the tangible and intangible supports and resources encompassed in that concept. This is particularly important as care becomes more and more specialized, and no one person can have all the expertise required.

\section{While a number of medical students and residents are exposed to research in some capacity, sustained commitment to a parallel research career is reported to be a challenge. In your opinion, what role should trainees play in advocating for support towards increased sustainability?}

RRM: Trainees should be strong advocates within their school and through national organizations. Parliamentarians will certainly be receptive to trainees and they would be keen supporters of a body of emerging professionals. So, trainees are uniquely positioned to make an impact both locally and nationally.

MGB: I think it's unfortunate that we don't encourage our students to put pressure on their universities. Students are undeniably creative and represent the future of research, so we as professors should more often empower them to advocate for research support. We should, as physicianscientists, tell them about our research endeavors as we teach the undergraduate and postgraduate medical trainees. We should also work with students to create a sustainability task force to sensitize and encourage medical schools to ensure at least one-year research training opportunities, which will prepare them to become better doctors and hopefully encourage some of them to become physicianscientists.

TJM: In the curricular plans that I helped develop at Dalhousie University, one of the most important features was to have a research project that spanned the full four years of medical school. The goal was not for every medical student to become a dedicated researcher, though it did facilitate good exposure for a subset that would go on to further develop their research careers. Rather, the aim was that all medical students would develop an awareness of the research process and a critical approach to consuming research publications. These projects were initially met with resistance; one of the reasons why medical students might not be keen to pursue research is that they see it as interfering with their primary goals in clinical training, such as passing the next exam. However, these longitudinal projects ultimately became a core element of the curriculum and the results far exceeded my expectations. Some students published in major journals, many presented their work at conferences and most appreciated the insights they gained and the mentors with whom they developed relationships. These mentors also advocated for the medical students when it came to residency position applications. 
Residency programs are now so prescribed by the Royal College and this leaves little room for development of a research career unless a student pursues such a career through a clinician-investigator program. On the other hand, the kind of research that clinicians are engaging in has diversified beyond the "wet-lab", and includes epidemiological research and quality improvement projects. This type of work can be better integrated into a resident's clinical work schedule even if dedicated research time can't be secured.

So, the ways in which medical students and residents can best advocate for support of their research careers is firstly, to engage in the research opportunities that are available. This includes existing programs facilitated through medical school and in residency. Or perhaps the most effective route is pursuing an $\mathrm{MSc}$ or a $\mathrm{PhD}$. Of course, these programs will typically require some form of institutional financial support. Trainees, in partnership with their institutions, can play an important role in raising these funds by soliciting donations from alumni. Similarly, endowed chairs are critical for junior researchers. In Alberta, I had success in raising endowed chair positions in which government would match private donations, and junior researchers may also be able to accomplish this. However, this can be a difficult sell since government, at both provincial and federal levels, will often counter that they have already allocated tax dollars to CIHR.

\section{We are now living in a world that becomes more globally interconnected every day. What role do you think international collaborations may play in saving physician-scientist career opportunities? How about the challenges of international funding and intellectual property theft?}

RRM: International collaborations are increasingly a necessity in order to address the growing complexity of today's research projects. Canadian funding agencies are recognizing this and will be making changes accordingly. I wouldn't be too concerned about intellectual property theft as medical researchers are generally well protected in this regard although the threat is increasing.

MGB: I think that if you are not seeking out or taking up international research opportunities, for example, international multi-centre trials, then you are missing the point of being a physician-scientist. It's important that we do not neglect developing nations and that we actively promote local research capacities whenever possible. There are lots of smart people all over the world and bringing resources with you to work with local talent can unlock incredible potential. In my experience, securing international funding has not been more difficult than domestic or local funding, but its value may be far more impactful when implemented in resource-limited regions. Similarly, we should not forget to seek out domestic research in under-serviced regions such as rural and indigenous communities. This includes northern Canada, where we are currently doing microbiota/microbiome studies. I believe the microbiota is the future of medicine in all fields!

I have had brief run-ins with intellectual property theft, but these were rather easily resolved even across international borders. So, it is nice to know that there is protection for intellectual property and that resolutions can sometimes be straightforward. I can't guarantee that there is respect for patents around the world, but if my ideas are saving lives, then I'm fine with that.

TJM: International collaboration is definitely important in the research world and can allow for studies that might not be feasible in one country alone. More and more, we are even seeing foundations such as the Bill \& Melinda Gates Foundation require that research involve international collaboration as part of their mission to facilitate international relations.

Intellectual property theft can occur even within a country and so I don't imagine that the risk of intellectual property theft is any greater when engaging in international research collaborations, but I don't know enough about the specific data on this. When it comes to collaboration, domestic or international, what's important is that you know your collaborators well.

\section{Do you think private industries have an important role to play in the future of physician- scientist opportunities?}

RRM: Nationally, it has been a complete sea change in the perspective on public versus private funding of research over the past several decades. The US has been well ahead of us in this area. We used to perceive relations with pharmaceutical industries as being on the so-called "dark side", but this is completely inappropriate. One might make a discovery that has the potential to improve health, but a researcher and her institution alone won't have the knowledge or capacity to develop and deliver: that is the territory of drug and biotech companies. These companies need the basic academic scientists and the scientists need them. Many of the drug companies have contracted their own research teams and shifted their investments into academe because they have found academe is the best 
source of original ideas that have transformative impacts. Today, there is no taint anymore in working with the private sector-they often provide training that is complementary to that found in university labs. Of course, the subject is no longer limited to drug development-there has been an explosion in device and software development as well.

MGB: There's no question that it helps to work with industry when the right opportunity arises; I would not have been able to accomplish much of my earlier work with antibiotics and antivirals without partnerships with private industries. Most academic scientists also have much to learn from private industry.

I think it is typically easier for physician-scientists than for basic scientists without clinical training to seek out industry support. This is probably related to the stage at which industry is looking to invest; that is often in clinical testing. Once you have learned the trade, you can apply it to your own innovations as we did by creating new companies that now sell our rapid molecular diagnostics tests in 50 countries and several other start-up companies by our CRI investigators who are developing new vaccines or even new potential drugs. Always remember that to innovate and bring products to the market, you need transformative science and transdisciplinary teams with a large and experienced clinical investigation unit to push forward inventions. Finally, many physician-scientists are working within diagnostics and pharmaceutical companies where they are playing important roles.

TJM: This is something that worries me. The private industry has goals that may differ from that of the physician-scientist. There's nothing wrong with this, but it's important that you recognize these differences up front. In the world of clinical trials, it's clear that little could be accomplished without private industry. But even when it comes to clinical trials, there are constraints that can come with funding from private agencies, such as the lack of interest in testing medications that are unlikely to be profitable. In these instances, I think there continues to be a crucial role for government to support trials.
8. Research training can differ significantly between disciplines, where the length of training and funding climate vary by discipline and field of study (e.g., basic vs. applied research). Do you think physician-scientist recruitment should be regulated according to area of study in order to encourage trainees/junior faculty to pursue projects that may be understudied, have relatively less certainty of success, or require more time?

RRM: I would not favour a rigid top-down approach in the intellectual realm. Instead, each school should offer training in fields where it is strong.

MGB: I don't think that recruitment of physician-scientists should be regulated according to area of study. Moreover, we certainly do not want our future physician-scientists to start their career working on projects that have less certainty of success or require more time. Recruitment should also be based on the need to increase capacity. When acquired immunodeficiency syndrome (AIDS) came along in 1981, it was a new disease and a new field that is still extremely active today. As there were no experts in AIDS, Medical Research Council (MRC) developed a special program to increase capacity in this area, and it worked very well as it led to transdisciplinary research teams that resulted in the transformation of MRC into CIHR and its pillars. When I came back to Université Laval in 1974, there was no specialty of infectious diseases in Canada and only a few of us doing research in this area; thus, I received a regular MRC grant and a "development grant" to increase capacity at U. Laval in infectious diseases. Just as there was at the creation of MRC and CIHR, there should be two major dedicated areas of funding: one for $\mathrm{PhD}$ scientists and one for physician-scientists. Naturally, the future of health research lies in young investigators. As for physicianscientists, whom I often call Olympians, they play a crucial role. But as we've discussed, they face added challenges that stem from the nature of their training and multi-faceted responsibilities (i.e., care, teaching, and research). The consequence of not having dedicated support for physicianscientists is now evident, as we have a shortage of these researchers.

TJM: Well, this approach never works. The whole venture of a clinician-scientist career is tough and so these researchers have to love what they're doing: you won't be successful if you are forced into a specific area. But we can try to make it easier to move into research areas identified as high demand. 
The wet-lab can certainly be a more difficult parallel commitment than the dry-lab, partly because one is more physically tied to the wet-lab. In addition, the relevant technology evolves so rapidly, making it difficult to keep up in the clinical arena. Because of these challenges, the MD/ $\mathrm{PhD}$ training program probably offers the greatest edge in succeeding in a wet-lab clinician-scientist.

\section{Conclusions}

Overall, interviewees held a cautious yet optimistic outlook for future of the Canadian physician-scientist, despite continued and newly emerging challenges.

In order to guide the relevant discussions and policies, there is a need for better data on the outcomes and trends of dual career training programs and the career parameters of physician-scientists. To this end, the publication by Skinnider et al. provides an important cross-sectional overview of the recent national figures on $\mathrm{MD} / \mathrm{PhD}$ outcomes [4], but this work will need to be continued in order to assess trends. Local survey data, such as in the work by Pietrobon et al. [5], and evaluations of specific novel initiatives in physician-scientist training [6-13], also serve to identify specific factors that facilitate success. Based on the frequency that the need for such data was raised by interviewees and in prior publications [1], there would be clear value in the establishment of a regularly updated and open access database on physician-scientist training and practice in Canada. To maximize participation, relevant organizations, including national funding agencies and advocacy groups, should consider mandating annual survey responses from program directors and physicianscientists.

There was agreement on the general understanding of the term "physician-scientist", but there was concern raised that some roles of the physician-scientist are increasingly being perceived as secondary and are therefore falling by the wayside. Namely, the roles of the physician-scientist as a clinician and a teacher should not be neglected. An active and thriving clinical presence provides physician-scientists with a unique advantage as researchers. Meanwhile, both clinical practice and teaching ensure continued rolemodelling, which will be crucial for the continuity of physician-scientist training, recruitment, and career prospects.

Basic science research is felt to have become a much more difficult pursuit for the physician-scientist. Aspiring physician-scientists who want to pursue basic science will need to rely increasingly on collaboration. Physicianscientists might also consider directing their focus to dry-lab research, but they should not feel restricted from basic- science, as their clinical insights are valuable across the translational research spectrum. Physician-scientists continue to play an important role in translational medicine, especially in leadership and in breaking research silos. More than ever, collaboration involving multi-disciplinary teams will be essential to research success. This includes international collaboration and working with private industry. Although there are grounds to advocate for dedicated areas of funding, such as for physician-scientists, a rigid top-down regulation of research focuses was thought to be too restrictive for the free enterprise that is needed in research. Funding agencies can play an important role in identifying research talent where it stands, anywhere from the wet-lab to the community clinic, and supporting them in knowledge translation [14].

We thank our outstanding interviewees for sharing these insights and their perspectives on the future of the Canadian physician-scientist. The Clinical and Investigative Medicine editorial team welcomes and encourages further commentary on this important area.

\section{Acknowledgements:}

We thank Roderick McInnes, Michel Bergeron, Thomas Marrie and Bev Holmes for sharing their incredible insights.

\section{Financial support}

This editorial was not financially supported by foundations, institutions, pharmaceutical, or private companies.

\section{References}

1. Strong MJ, Busing N, Goosney DL, et al. The Rising Challenge of Training Physician-Scientists:

Recommendations from a Canadian National Consensus Conference. Acad Med. 2018;93(2):172-8. doi:10.1097/ ACM.0000000000001857

2. Jain MK, Cheung VG, Utz PJ, Kobilka BK, Yamada T, Lefkowitz R. Saving the Endangered Physician-Scientist - A Plan for Accelerating Medical Breakthroughs. N Engl J Med. 2019;381(5):399-402. doi:10.1056/NEJMp1904482

3. Garrison HH, Deschamps AM. NIH research funding and early career physician scientists: Continuing challenges in the 21st century. FASEB J. 2014;28(3):1049-58. doi:10.1096/ fj.13-241687

4. Skinnider MA, Squair JW, Twa DDW, et al. Characteristics and outcomes of Canadian $\mathrm{MD} / \mathrm{PhD}$ program graduates: a cross-sectional survey. CMAJ Open. 2017;5(2):E308-E314. doi:10.9778/cmajo.20160152

5. Pietrobon A, Chehadé L, Beaudry-Richard A, Keller BA, Schlossmacher MG. Performance report for a 10-year-old 
$\mathrm{MD} / \mathrm{PhD}$ program: A survey of trainees at the University of Ottawa. Clin Invest Med. 2020; in press.

6. Levit A, Yin C, Lewis JF. Fourth annual clinician scientist trainee symposium at the schulich school of medicine \& dentistry. Clin Invest Med. 2019;42(4):E46-E49. doi:10.25011/ cim.v42i4. 33345

7. Fitzgerald K, Taws M, Calic A. Calling all Emerging Health Leaders: A unique professional development opportunity awaits you! Clin Invest Med. 2019;42(1):E19-E20. doi:10.25011/cim.v42i1.32386

8. Seneviratne AK, Zahr SK, Mirali S, et al. Addressing the need for a new generation of young translational researchers that focuses on societal impact: The Apollo Toronto Story. Clin Invest Med. 2019;42(3):E14-E16. doi:10.25011/ cim.v42i3.33088

9. Anchouche S, Liu J, Vucetic S, Santerre K, Zhou TE. The Vision Health Research Network and its commitment to the scholarly development of its trainees. Clin Invest Med. 2019;42(4):E42-E45. doi:10.25011/cim.v42i4.33110

10. Mirali S, Fan K, Cook EK, Marvasti TB. Piloting a long distance clinician scientist trainee mentorship match in Canada. Clin Invest Med. 2020;43(1):E5-E8. doi:10.25011/ cim.v43i1.33649

11. Whittaker HT, Skerritt L, Dankner M, Eisenberg MJ. An exercise in scientific writing for physicians in training. Clin Invest Med. 2020;43(1):E35-E38. doi:10.25011/ cim.v43i1.33647

12. Koren G, Gabay L, Kuchnir J. A clinician-researcher training program for family medicine residents. Clin Invest Med. 2019;42(3):E35-E39. doi:10.25011/cim.v42i3.33090

13. Ward R, Delaloye N, Logan L, Jenkins S, Hollenberg MD, Rabi DM. Proceedings from the 9th Annual University of Calgary leaders in medicine research symposium. Clin Invest Med. 2019;42(2):E1-E18. doi:10.25011/cim.v42i2.32811

14. Holmes B, Scarrow G, Schellenberg M. Translating evidence into practice: The role of health research funders. Implement Sci. 2012;7(1):39. doi:10.1186/1748-5908-7-39 